\title{
O que pode o Sistema Único de Saúde em tempos de necropolítica neoliberal?
}

\author{
What can the Unified Health System do in times of neoliberal \\ necropolitics?
}

Rafael Agostini', Adriana Miranda de Castro'

DOI: 10.1590/0103-11042019S813

\begin{abstract}
RESUMO Na redemocratização do Brasil, 'nós, o povo', comprometidos com a cidadania a materializamos na Constituição Federal de 1988. A Constituição Cidadã, refletindo a sinergia entre trabalhadores da saúde e necessidades da população, garantiu o direito universal e igualitário à saúde. A partir daí, há ataques crescentes do capital ao projeto ético-político que funda o Sistema Único de Saúde (SUS); bem como aumenta, entre alguns grupos da sociedade, uma percepção estigmatizante sobre SUS. Com os investimentos da racionalidade necropolítica neoliberal em ser corpus teórico central da organização da sociedade e do Estado, assiste-se à expansão da precariedade com ataques às políticas de seguridade social e de inclusão da diversidade. Tal agenda se expressa no SUS, principalmente, pelo congelamento dos investimentos sociais e pela destinação de recursos a ações que contrariam a autonomia dos sujeitos. Considerando os ataques hodiernos ao SUS e ao Estado de Bem-estar Social, pergunta-se: como resistir? A aposta é que se (re)tome o diálogo entre 'nós, o povo' para construir um movimento radical em defesa de 'uma vida possível de ser vivida' para todos. O SUS tem e terá um papel estratégico, pois continua sendo reconhecido como fundamental na garantia da vida e da equidade.
\end{abstract}

PALAVRAS-CHAVE Sistema Único de Saúde. Capitalismo. Política.

\begin{abstract}
In the redemocratization process of Brazil, 'we, the people' committed to the citizenship that led to the promulgation of the 1988 Federal Constitution. The 'Citizen Constitution', mirroring the synergy between health workers and the population's needs, granting health as a right directly related to the notions of universality, integrality, and equity. We have been struggling with severe attacks of the Capital against the ethical-political agenda that founds the Unified Health System (SUS) and the stigmatized perception that a part of society has of it. With the attempt of the neoliberal necropolitical rationality to become the theoretical corpus of society and State, we've been witnessing the increase of precarity through the dismantling of social security and to minorities policies. The impact on the SUS took place through a decrease in financing and allocation of resources to actions against the autonomy of the subjects. Considering these attacks against the SUS and the Welfare State, we ask: how to resist? Our bet is: to retake the conversation among 'we, the people', in order to build a radical movement towards 'a life possible to be lived' for everyone. The SUS has and will continue to have a strategic role, as it continues to be recognized as fundamental in guaranteeing the right to live and equity.
\end{abstract}

KEYWORDS Unified Health System. Capitalism. Politics.

'Fundação Oswaldo Cruz (Fiocruz) - Rio de Janeiro (RJ), Brasil.

rafael.agostini.vbg@gmail. com 
A vida é uma causa em si mesma.

É a causa de todas as causas.

Pepe Mujica.

\section{Introdução}

A Constituição brasileira de 1988 é efeito e materialização de uma história nacional de lutas políticas pela garantia de direitos. Após anos de ditadura e com um cenário externo marcado pela rápida transformação dos mecanismos de funcionamento do capitalismo, nossa sociedade tomou como compromisso assegurar direitos sociais, políticos e econômicos. No centro de nossas preocupações, a garantia da liberdade e da vida para todos os brasileiros em sua diversidade.

O Sistema Único de Saúde (SUS) é parte do acúmulo de batalhas pela redemocratização e por políticas sociais inclusivas', que se concretizaram na promulgação do texto constitucional. Partindo da afirmação "a saúde é direito de todos e dever do Estado"2, assumiu-se a necessidade de formular, implementar e fiscalizar políticas e redes de serviços que orientassem e operacionalizassem a promoção, a proteção e a recuperação da saúde dos brasileiros.

Fundado na universalidade e na integralidade, o sistema de saúde brasileiro adotou como princípios organizativos a regionalização e a hierarquização, a descentralização e o comando único, e a participação e o controle social. Nesse sentido, o 'dever do Estado’ faz-se de forma tripartite e no diálogo com a sociedade posto que, legalmente, é imprescindível a concertação entre os entes federados e conselhos de saúde.

Desde a Constituição e da Lei n ${ }^{0} 8.080 / 90$, o SUS experimenta as consequências de disputas e tensionamentos políticos que atravessam nossa sociedade, que se concretizam em uma série de emendas à Constituição, leis, decretos, portarias e normas nem sempre favorecedora do projeto ético-político que o sustenta.

No entanto, no mesmo período, assistimos e trabalhamos pelo fortalecimento e pela expansão do nosso sistema público de saúde, tendo especial sucesso na capilarização, financiamento e qualificação da Atenção Primária à Saúde (APS), no controle de doenças infectocontagiosas, na cobertura vacinal, na redução da mortalidade materna e infantil, na segurança alimentar, no controle do tabagismo e nas políticas de saúde mental e HIV/Aids (Vírus da Imunodeficiência Humana/Síndrome da Imunodeficiência Adquirida) ${ }^{3-9}$.

A despeito de impasses e de gargalos na garantia do acesso universal e integral à saúde, vimos persistir a defesa da saúde pública como cláusula pétrea de nosso contrato social desde a redemocratização até o golpe de 2016.

A modulação do capital que emerge a partir da década de 1980, crescentemente globalizada, multipolar e financeiro-especulativa ${ }^{10}$, produz, em 2008, uma das suas maiores crises cíclicas, que significou empobrecimento para a maioria das populações e fator de enriquecimento para alguns. No Brasil, os efeitos deletérios da crise foram inicialmente contidos por investimentos, políticas públicas não regressivas e grandes eventos. Porém, logo se fizeram sentir com o agravamento da especulação neoliberal e com a orquestração de elementos que propiciariam uma crise política.

Sob o argumento do ajuste econômico e do combate à corrupção, os antagonismos entre projetos civilizatórios e entre diferentes grupos sociais - classes sociais, diria nosso amigo barbudo"1'! - se explicitaram e são fomentados. Viu-se (re)emergir um conjunto de discursos e práticas autoritárias e conservadoras, cuja novidade é a articulação entre necropolítica ${ }^{12}$ e neoliberalismo ${ }^{10}$ e seu modus operandi digital e em rede ${ }^{\mathbf{1 3}}$.

Nesse cenário sombrio, que gestou, por exemplo, o congelamento dos recursos da saúde e educação por 20 anos a despeito das análises sobre nossa polarização epidemiológica $^{14}$ e transição demográfica ${ }^{15}$, nos interessa pensar na (re)construção do Brasil. Assim, se ainda carregamos as chagas da escravização dos povos africanos, do genocídio dos povos tradicionais e dos projetos eugênicos que 
trouxeram europeus para 'embraquecermos', também experimentamos a potência transformadora de políticas públicas socialmente referenciadas como a inclusão plural dos jovens nas universidades, da participação social na construção do SUS, da reversão das tendências de aumento da população vivendo abaixo da linha de pobreza.

É nesse cenário e almejando outros horizontes que nos perguntamos: o que pode o SUS? O que pode o sistema de saúde público brasileiro ante a necropolítica ${ }^{12}$, que se quer projeto ético-político hegemônico e fundante do Estado pós-2016?

\section{A Reforma Sanitária e seu projeto ético-político}

Se uma constituição é efeito de tensões, contradições e acordos possíveis em dado momento histórico de uma sociedade, podemos dizer que, em 1988, após longo inverno, fizemos uma aposta pelo Estado de bem-estar social à europeia ${ }^{16}$. Embora haja questões político-epistemológicas em afirmar 'nós, o povo', como lembra Butler17, parece adequado dizer que a promulgação da Constituição brasileira ${ }^{2}$ envolveu uma série de atos - discursivos ou não -, em que 'nós' nos comprometíamos e reivindicávamos o direito a "uma vida possível de ser vivida"17(167) para todos.

Nesse sentido, a criação do SUS foi efeito de um processo de acúmulo de saberes e práticas que aconteceram, por um lado, à margem do discurso hegemônico e, por outro, na ocupação de espaços na máquina estatal por grupos vinculados ao pensamento progressista ${ }^{18}$.

Articulavam-se movimentos sociais pela redemocratização do País, pela anistia, pelo enfrentamento da desigualdade social e redução da extrema pobreza e pelo fortalecimento da sociedade civil em torno do imperativo ético de defesa da vida, em que igualdade e equidade ${ }^{19}$ convergiam para a concretização da saúde como direito social16,20.

Sob o significante 'movimento sanitário', reuniram-se experiências plurais de oposição ao status quo, que guardavam diferentes pontos de inserção na cena política, nos diversos campos de conhecimento envolvidos na produção da saúde e nos jogos de poder que atravessavam a disputa pelo sentido da saúde no País.

Em um cenário mundial de hegemonia neoliberal e questionamento da capacidade econômica e da competência gerencial do Estado em oferecer bens e serviços à população, o movimento da Reforma Sanitária - a despeito de suas contradições internas - e a atuação de parlamentares do campo da saúde na Câmara dos Deputados, a partir de 1976-1978, garantiram o processo institucionalização do SUS ${ }^{\mathbf{1 8 , 2 0}}$.

Ancorada no aumento de adoecimentos e mortes, na impossibilidade de acesso de inúmeros brasileiros à atenção à saúde, na expansão das reflexões teóricas comprometidas com propostas concretas para melhoria da qualidade de vida das classes trabalhadoras e na experiência de implementação de projetos municipais de gestão da saúde alinhados à garantia da saúde pública de qualidade, a concretização do SUS integrava um projeto ético-político e civilizatório. Tal projeto toma a saúde como direito garantido por políticas sociais e econômicas, integra saúde à seguridade social e afirma a defesa da cidadania a partir de direitos sociais universais e inalienáveis ${ }^{\mathbf{2} 21}$.

Entretanto, há uma distância considerável entre o que foi registrado nos textos constitucional e infraconstitucionais para a operação do SUS e como ela de fato se deu e se dá na experiência dos cidadãos.

Em que pesem os discursos em defesa do SUS, na maior parte da chamada 'Nova República', assistiu-se à implementação de ações que facilitaram a privatização e a mercantilização e, concomitantemente, operacionalizaram a política de saúde pública sob a lógica da contenção de gastos e da seleção das demandas populacionais a serem atendidas ${ }^{\mathbf{2 0}}$.

A partir da perspectiva neoliberal e, muitas vezes, sob influência dos interesses corporativistas, vimos a implementação da política de saúde ser alvo de estratégias de contenção de 
gastos, de contingenciamento e, finalmente, de congelamento dos valores pelos próximos 20 anos. Sob o discurso de 'crise econômica', de equilíbrio das contas públicas e de austeridade, o SUS é tomado como despesa a ser racionalizada. Negando-o, inclusive, como área produtiva de grande impacto na economia brasileira ${ }^{\mathbf{2 0}, 21}$.

Em um mundo que instiga a competitividade e a produção de sujeitos empresários de $\mathrm{si}^{10}$, a queda de braço entre um projeto ético-político marcado pela defesa da igualdade, universalidade e equidade e um modus operandi neoliberal, individualista e privatista tem sido intensamente midiatizada.

Hegemonicamente, a narrativa dos grandes meios de comunicação diz da falta de gestão, infraestrutura, tecnologia, insumos, profissionais, transparência, honestidade. Assim, o SUS emerge, na maioria das vezes, como exemplo paradigmático da falência do Estado na oferta de bens e serviços. Tal narrativa, associada à pressão do mercado privado de saúde, tem produzido e espalhado no imaginário da sociedade brasileira a certeza da precariedade do sistema público, de que buscá-lo é falta de opção e de que um atendimento público de qualidade é 'sorte'22.

Nesse cenário, o estigma em relação ao SUS e a ser usuário da saúde pública - como se todos não o fôssemos! - que pode ser associado às classes médias ${ }^{22}$ se espalha e ocupa, por exemplo, a agenda dos trabalhadores e seus sindicatos. Como presenciamos, por exemplo, durante assembleia de greve dos trabalhadores da construção civil nas obras para a copa do mundo de futebol no Rio de Janeiro, em que havia grande indignação porque um trabalhador vítima de um acidente foi levado à emergência do SUS e se reivindicava plano de saúde coletivo para operários e suas famílias.

Reigada e Romano ${ }^{22}$ verificaram que, mesmo diante das experiências positivas de cuidado à saúde, persiste a desconfiança em relação à política pública de saúde. As autoras apontam que, por um lado, há desconhecimento sobre a organização e funcionamento do SUS; por outro, em uma sociedade de consumo, tende a prevalecer a lógica em que os direitos são compreendidos a partir da relação de prestador-consumidor. Investe-se, pois, no esvaziamento do conceito de cidadania ${ }^{21}$.

Poderíamos analisar o tensionamento constante entre os sistemas público e privado de saúde que coexistem no Brasil e o papel tático da mídia nos jogos de verdade que nos atravessam com múltiplas lentes. Porém, interessa-nos justamente pensar a relação do SUS com 'nós, o povo'17.

Butler ${ }^{17}$ afirma que a expressão 'nós, o povo' é imanente à constituição daqueles que assim se designam em um espaço público, real ou virtual, que lhes dá suporte à existência, ao aparecimento. $\mathrm{O}$ significante implica um conjunto plural de corpos, os quais estão diferentemente expostos à precariedade e são, concomitantemente, alvos e agentes de disputas políticas.

A demarcação 'nós, o povo' não assegura harmonia, uniformidade de interesses nem convivência pacífica. Porém, não impede que pensemos na construção de propostas convergentes, que nos reúnam no estabelecimento de uma ética da convivência, marcada pela igualdade e pela minimização da precariedade ${ }^{17}$.

Entendemos que o projeto ético-político de nação do movimento da Reforma Sanitária, inscrito na Constituição de 1988 e vivo no cotidiano do SUS pelo País, é uma dessas propostas convergentes. Entretanto, cabe perguntar: perdemos a capacidade de reunir 'nós, o povo' entorno dessa proposta? Como resistir na defesa da vida e da saúde pública em tempos de necropolítica neoliberal?

\section{Necropolítica neoliberal e efeitos no Brasil}

Partindo das reflexões foucaultianas sobre o biopoder, o filósofo Mbembe ${ }^{\mathbf{1 2}}$ se pergunta se essa noção é suficiente para pensar as maneiras contemporâneas de funcionamento do poder, "em que o político, por meio da guerra, da resistência ou da luta contra o terror, faz do assassinato do inimigo seu objetivo 
primeiro"12(6). Além disso, ilumina os processos que recorrem ao Estado de exceção e à noção ficcional de inimigo como base normativa do direito de matar. Em sua reflexão quanto ao lugar da vida, da morte e dos corpos humanos nos regimes de poder contemporâneos, o autor desloca a proposta foucaultiana partindo da análise dos cenários coloniais e neocoloniais e introduz a ideia de necropolítica.

O conceito de necropolítica como paradigma da divisão entre segmentos sociais, que regulamenta - e regulariza - o poder de gestão da vida, vai ditar quem pode viver e quem deve morrer para garantir o funcionamento da máquina de guerra capitalística. Para tanto, produz o esvaziamento do status político dos sujeitos e sua redução a um emaranhado bioquímico inumano, buscando assegurar a legalidade de toda sorte de genocídios, por ação bélico-militar ou por abandono.

A máquina de guerra capitalística, no contemporâneo, age para perpetuar os ciclos de exploração da grande maioria por alguns poucos na (re)composição das operações necropolíticas e neoliberais ${ }^{23}$.

Valverde ${ }^{23}$ busca evidenciar como a agenda neoliberal instaura políticas de morte. A autora analisa que as frações das classes dirigentes não têm mais no aparato policial a única estratégia de eliminar quem não interessa ao sistema capitalista. Os sujeitos que não produzem, não consomem ou representam perigo a arquitetura da desigualdade do capitalismo são alvo de uma 'violência discreta', que os deixa morrer silenciosamente a partir de uma agenda de austeridade radical e exclusão. Atingindo todos os trabalhadores, essa agenda é especialmente cruel com aqueles que vivem às margens, onde vulnerabilidade e precariedade ${ }^{17}$ ganham força.

Segundo Valverde ${ }^{23}$, essa estratégia é exitosa na medida em que o sistema neoliberal fomenta que os minimamente incluídos desconfiem, como regra, dos excluídos, não se identifiquem com o seu sofrimento nem se solidarizem com eles. Alimenta-se, a ideia de que os excluídos são essencialmente diferentes, e não confiáveis, potencialmente desagradáveis e perturbadores, pois 'ameaçam' a ordem pretensamente perfeita do socius. Destarte, os trabalhadores são ludibriados pela imprensa hegemônica e por um complexo e sofisticado arsenal cultural - a endossar a classe dirigente para quem os excluídos são imundos, com maus hábitos e responsáveis por seu próprio sofrimento.

$\mathrm{Na}$ leitura de Butler ${ }^{17}$ a produção desse outro como inimigo articula-se ao uso que o neoliberalismo faz da noção de responsabilidade. Articulada ao individualismo competitivo e à autossuficiência como valor moral, a responsabilidade pressiona o sujeito a buscar incessantemente àquilo que estruturalmente o sistema o impedirá de conseguir. Assim, se estabelece a precariedade como condição real para uns e ameaça constante e contínua para todos. Dispensável ou potencialmente dispensável, o sujeito experimenta a ansiedade de maximizar seu próprio valor de mercado e 'matar seus inimigos'.

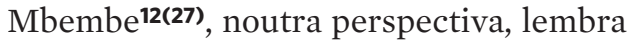
que não se pode analisar a articulação terror/ Estado desde a modernidade sem abordar a escravidão - "uma das primeiras manifestações da experimentação biopolítica”. A escravidão distinguia claramente quem era e quem não era gente e, no caso brasileiro, como aponta Souza $^{24}$, foi a instituição que moldou nossa forma de organização social e continua viva nos afetos e na mentalidade da população brasileira, notadamente da classe dominante e de frações das classes médias.

A promulgação da Lei Áurea, como se fosse benesse concedida aos povos escravizados, evidentemente não teve o condão de transformar 'propriedades' em gente da noite para o dia. Ao contrário, parece ter perpetuado um imaginário de que há populações inteiras 'indignas' e 'fracassadas', que merecem: a morte, a partir da 'segurança pública', ou a filantropia, na perspectiva de uma saúde para 'quem não pode pagar'.

Fazendo dialogar Mbembe ${ }^{12}$ e Ribeiro ${ }^{25}$, encontramos no Brasil uma classe dominante infecunda, composta por descendente de 
senhores de escravos, que trazem na alma o pendor de quem compra um ser humano e busca tirar, sob o chicote, aquilo que ele pode dar, da forma mais descartável possível, como carvão que se queima para produzir e obter lucro. Numa postura perversa e pervertida - necropolítica -, fazem do País uma verdadeira máquina destinada a moer gente, como aponta Darcy Ribeiro ${ }^{25}$.

No Brasil, em certa medida, a necropolítica sempre foi patrocinada por diversas frações desta classe dominante e sua genealogia se confunde com a história do País. Entretanto, diversos mecanismos de contingenciamento de suas operações foram conquistados, por exemplo: a institucionalização da participação e controle social na elaboração e gestão de políticas públicas, a implementação de políticas de redistribuição de renda e de mecanismos de garantia de equidade e representatividade - como as cotas para populações negras e indígenas acessarem o ensino superior.

Ocorre que, desde o golpe político-jurídico-midiático ${ }^{26}$ de 2016, parece que nossos acordos de garantia de cidadania ${ }^{21}$ se esgarçaram, foram colocados sob suspeita na sociedade e sob ataque do próprio aparelho do Estado. Investiuse na ruptura dos nossos pactos constitucionais e na construção de uma 'ponte para o século XIX'27. Um exemplo foi a implementação da contrarreforma trabalhista, que trouxe de volta a precariedade das condições de trabalho e a desresponsibilização patronal ${ }^{28}$.

Tal cenário parece se agravar no período pós-eleitoral de 2018, levando-nos a perguntar em que medida o projeto necropolítico não passou de inspiração a corpus teórico central da organização da máquina de guerra estatal. Por um lado, vemos o acirramento dos ataques à seguridade social, à educação eà diversidade que foram escamoteados na campanha e agora surgem em campo aberto. Por outro, assistimos à ação ostensiva - e assassina - das forças de segurança pública nos territórios periféricos e a invisibilização das mortes de lideranças de direitos humanos e ambientais.

De saída, o governo eleito recuperou a antirreforma da previdência rechaçada pelos brasileiros no pós-golpe e a transformou em sua principal bandeira. A proposta original do governo estabelece uma idade mínima de 65 anos para homens e 62 para as mulheres, amplia para 40 anos o tempo de contribuição para a aposentadoria integral e legaliza pagamentos menores que um salário mínimo. Ademais, decreta o fim da aposentadoria especial para professores do ensino básico e pequenos produtores rurais e aumenta para 70 anos a idade mínima para que idosos em condição de miserabilidade acessem o Benefício de Prestação Continuada (BPC) ${ }^{\mathbf{2 9}}$.

$O$ texto encaminhado cria dificuldades e, em boa parte dos casos, inviabiliza o acesso à aposentadoria. Diante da dificuldade de inserção ininterrupta no mercado formal por períodos tão longos, das altas taxas de desemprego que chegam a $20 \%$ em certas regiões - e da baixa expectativa de vida em alguns estados da federação, se for aprovada a nova legislação condena à morte os trabalhadores mais pobres antes que possam se aposentar ${ }^{30,31}$.

O cerceamento aos benefícios por morte, o fim da multa sob o Fundo de Garantia por Tempo de Serviço (FGTS) e do seu recolhimento para aposentados que seguem em atividade laborativa e a proibição de exigir judicialmente medicamentos de alto custo, tal como se encontra na proposta enviada ao parlamento, constrangem economicamente os que dependem da seguridade social para sobreviver.

Além disso, representantes do governo federal vêm declarando que as Normas Regulamentadoras de condições de segurança e saúde no trabalho serão reduzidas em pelo menos $90 \%^{32}$. Os trabalhadores que serão submetidos a condições insalubres e inseguras de trabalho decerto não serão magistrados, parlamentares ou militares de alta patente, nuançando a segmentação que nos fala Mbembe ${ }^{12} \mathrm{e}$ fixando quem merece trabalho decente e quem deve se contentar às circunstâncias ditas possíveis ${ }^{33}$.

Outra medida - talvez, a mais obviamente vinculada à guerra e ao terror - que fala do despudor da ação necropolítica no Brasil é a mudança, por decreto, na legislação sobre 
posse e porte de armas. Embora saibamos que o Estatuto do Desarmamento não tem sido capaz de fazer regredir o número de homicídios por armas de fogo, é notório que conteve a corrida armamentista ${ }^{34}$ e derrubou em mais de $250 \%$ a taxa de crescimento dos mortos, salvando mais de 100 mil vidas, especialmente entre os jovens ${ }^{35}$. A despeito das informações existentes e da violência já vivenciada no País, o governo federal insiste em liberar armas de fogo para cidadãos civis. Para todos? Será?

Na primeira versão do decreto ${ }^{36}$, a aquisição e o registro de armas para posse em domicílio ou estabelecimentos comerciais foi consideravelmente facilitada para vários grupos. Na segunda ${ }^{37}$, o porte foi garantido a todos os políticos, do presidente aos mais de 57 mil vereadores brasileiros. Por ele, se permite andar armado em espaços públicos a jornalistas, oficiais de justiça, advogados, conselheiros tutelares, agentes reguladores de trânsito e caminhoneiros, totalizando quase 20 categorias profissionais.

Latifundiários, por sua vez, passaram a ter permissão de utilizar armas não apenas dentro de casa, mas em toda a extensão da sua propriedade. A importação de armas e munições é liberada para civis e se aumenta o número de projéteis que podem ser adquiridos - na primeira versão do texto chegou-se a incluir fuzis entre as armas que poderiam ser compradas pelo cidadão comum. Além disso, é previsto o acesso a clubes de tiro para menores de idade com autorização dos pais.

Por fim, a importância da preservação do meio ambiente para a manutenção e qualidade da vida é sistematicamente ignorada. À liberação indiscriminada de quase duas centenas de agrotóxicos, ignorando seus efeitos trágicos para a saúde ${ }^{\mathbf{3 8}}$, se soma a redução significativa do número de multas aplicadas pelo Ibama e a intenção de romper parcerias com organizações da sociedade civil atuantes na proteção ambiental. As críticas ao acordo de Paris sobre mudanças climáticas culminaram no cancelamento - por parte do Brasil - do encontro regional da Organização das Nações
Unidas (ONU) sobre mudanças climáticas e na recusa em sediar a Conferência das Nações Unida sobre Mudanças Climáticas em 2025.

Se no âmbito das linhas de determinação social da saúde, exemplificadas acima, os impactos na morbimortalidade e na qualidade de vida da população podem ser intensos, ao focarmos especificamente a organização do setor sanitário a situação não é menos preocupante. Pensando no projeto ético-político que funda o SUS, gostaríamos de apontar como analisadores da situação três campos: a Estratégia Saúde da Família (ESF) e as políticas de saúde mental e HIV/Aids.

A ESF, no Brasil, se mostrou indispensável para o alcance de uma cobertura universal do SUS e era, antes da crise, responsável prioritária pelos cuidados em saúde de mais da metade da população brasileira, alcançando em números absolutos mais de 110 milhões de pessoas. A sua maior expressão em regiões de maior vulnerabilidade vem evidenciando o compromisso prioritário com a redução das iniquidades. Ainda que os resultados não possam ser isolados, um exemplo do êxito da ESF é que as internações por causas sensíveis à APS reduziram-se consideravelmente no período de 2001-2016, passando de 120 para 66 por 10 mil habitantes ${ }^{39}$.

Todavia, Rasella e colaboradores ${ }^{40}$ apontam os malefícios das medidas de austeridade como a EC-95 e a consequente redução da cobertura da ESF com os recuos no Programa Mais Médicos. A projeção é de que a taxa de mortalidade prematura, aquela que acontece antes dos 70 anos, pode aumentar até 8,6\% até 2030, o que significa quase 50 mil mortes que poderiam ser evitadas. O número, como apontam os pesquisadores, provavelmente está subestimado já que óbitos que não são classificados como sensíveis à APS, mas sobre os quais a ESF teria alguma incidência, não estão contabilizados

Noutro artigo ${ }^{\mathbf{4 1}}$, os pesquisadores afirmam que a garantia dos níveis de investimento significaria salvar a vida de quase 20 mil crianças de até cinco anos e evitar a internação de mais 
de 120 mil delas, em comparação com um cenário em que programas de proteção social têm sua cobertura significativamente reduzida pela política de cortes de longo prazo. Evidentemente os impactos serão mais significativos nos municípios mais pobres, atingirão de forma mais cruel às populações mais vulneráveis e incidirão sobre o aumento das desigualdades.

O imbricamento proposto pelo movimento de Reforma Sanitária entre uma concepção ampla de saúde e a radicalização da democracia é notório em todo o SUS, mas especialmente em áreas como a saúde mental e o HIV/Aids, que convocam posicionamentos ético-políticos de distintos atores sociais e proporcionam não apenas desafios importantes, mas enormes inovações no âmbito da atenção à saúde. É justamente por isso, não por acaso, onde acontecem os primeiros ataques.

No caso da saúde mental, a 'nova política' já nasce velha e recupera a institucionalização do usuário, o uso de eletrochoque no SUS e as internações de crianças em hospitais psiquiátri$\cos ^{42}$. Especificamente no caso dos problemas causados pelo uso abusivo de álcool e outras drogas, o texto define a abstinência como única estratégia e institui o financiamento público massivo para comunidades terapêuticas, privilegiando o asilamento. Verifica-se, pois, uma vitória do mercado de internações com a negação dos usuários como sujeitos de direito e a 'permissão' estatal para sua institucionalização compulsória e à revelia do seu desejo.

Quanto ao HIV/Aids, categorias reconhecidamente implicadas no sucesso de estratégias de prevenção e fundamentais à garantia de direitos e à promoção da saúde de populações mais vulneráveis ${ }^{\mathbf{4 3}}$ como 'gênero', 'diversidade sexual', 'direitos sexuais e reprodutivos' e 'redução de danos' vêm sendo questionadas. Partindo de uma racionalidade que apela a valores moral-religiosos, investe-se em privatizar o debate, retirando-o do âmbito da garantia de direitos pelo Estado e lançando-o ao 'foro íntimo' das famílias. A reboque dos 'novos' tempos, materiais sobre estratégias de prevenção e exercício mais saudável da sexualidade voltados às pessoas transexuais e aos adolescentes foram censurados. Recentemente, o desaparecimento do programa brasileiro de HIV/Aids na estrutura formal do Ministério da Saúde é sinal de alerta para a ruptura com a garantia de estratégias de educação, prevenção e, até mesmo, de acesso à medicação antirretroviral em todas as situações de exposição ao vírus - já questionado por atores da arena pública.

\section{Então, o que pode o SUS?}

Diversos países, além do Brasil, têm sistemas públicos de saúde, mas o maior e 'mais desenvolvido' entre estes, a Inglaterra, tem apenas 130 mil km² de extensão e uma população que não alcança 65 milhões de pessoas - números próximos aos do estado de São Paulo. No caso brasileiro, por sua vez, falamos de quase 220 milhões de habitantes de diversos pertencimentos étnicos, socioculturais e econômicos espraiados em mais de 8 milhões de $\mathrm{km}^{2}$. Garantir, nesse contexto, um sistema público, gratuito e de qualidade é um desafio grande e inédito.

A saúde ainda é apontada pelo povo brasileiro, em pesquisas de opinião, como uma das áreas que devem ser priorizadas pelas políticas públicas $^{\mathbf{4 4}, 45}$. Nas mesmas pesquisas, o SUS aparece como alvo de críticas e são revelados gargalos graves. Apesar disso - e da narrativa construída por setores da mídia hegemônica - os resultados também indicam que grande parte da população utiliza o SUS, defende que ele se mantenha como modelo de acesso universal e, inclusive, acredita ser necessário maior aporte de recursos.

Entretanto, num projeto necropolítico neoliberal, parece que já não é preciso qualquer pudor em atacar políticas, instituições e serviços públicos, em especial quando seu principal efeito na sociedade vincula-se à redução das desigualdades sociais e à garantia de direitos e, sobretudo, de equidade. Assim, tornou-se comum no noticiário encontrar o desmonte 
de ações para acesso à renda mínima, à educação - sobretudo, embora não só, universitária - à demarcação de terras indígenas entre outras. Bem como a veiculação explícita de propostas de fim da gratuidade do ensino público e do próprio SUS.

À primeira vista, tais movimentos de privatização total, parecem não causar qualquer indignação uma vez que às grandes corporações midiáticas não interessa a veiculação do dissenso nem de discursos contrários à mercantilização. Contudo, isso não se sustenta quando ouvimos as expectativas da população.

Entrevistas nas portas das unidades de saúde, na casa das pessoas que esperam cirurgias há anos ou nas filas de vacinação em épocas de 'crise' como da febre amarela, a maioria da população anseia por um SUS que funcione, não que acabe. Dentre os trabalhadores, a solução dos problemas que percebem e experimentam no sistema de saúde passa por mais e melhor investimento em saúde pública - nunca por menos. Conforme pesquisa realizada pelo Datafolha em 2018, a saúde continua como prioridade política $\mathrm{n}^{\circ} 1$ para $39 \%$ dos entrevistados e $88 \%$ deles defendem que o SUS permaneça gratuito, integral e universal ${ }^{46}$.

Num cenário em que a população em geral e, especificamente, as mais vulneráveis vivem sob o impacto de uma série de violências por ação e/ou omissão dos vários setores/atores sociais não é desprezível que o SUS, em que pese às violências que nele também ocorrem ${ }^{47-50}$, ainda seja desejado e valorizado.

Considerando os usuários diretos dos serviços de saúde percebemos que se há uma fatia da população que estigmatiza o SUS, notadamente as classes médias urbanas ${ }^{22}$, também há grupos que reconhecem sua importância. Noutra direção, há aqueles que, mesmo não recorrendo à clínica realizada no SUS, reconhecem sua importância em campos como vigilância sanitária, controle de zoonoses, vigilância ambiental, produção de insumos, inovação tecnológica e formação de profissionais. Assim, é difícil dizer que o sistema público de saúde brasileiro não esteja presente na vida da maioria de 'nós, o povo'17.
Entendemos que essa presença na vida de quase $100 \%$ dos brasileiros e o valor que lhe é dado por muitos de nós oferecem uma grande potência ao SUS. No entanto, é urgente que trabalhemos na recomposição das relações de pertencimento entre políticas públicas, bem público e cidadãos. É importante que retomemos as bases do projeto ético-político que nos permitiu chegar até aqui, mesmo que aos trancos e barrancos. É fundamental que saiamos às ruas - físicas ou virtuais -, para explicitar nosso compromisso com a vida, nossas dificuldades e convocar a sociedade para um processo de reflexão e construção coletiva menos aprisionado nos arranjos organizacionais já estabelecidos e, muitas vezes, enfraquecidos.

Campos $^{\mathbf{5 1 , 5 2}}$ tem alertado da necessidade de nos movermos em direção a outros modos de fazer/defender a saúde pública a fim de não perdermos a potência de nosso projeto ético-político. Por um lado, o autor nos convoca a deslocarmos nossas práticas de ações que tentam manipular desejos, valores e sensações dos sujeitos e seus corpos em função de necessidades das normas estabelecidas pela epidemiologia ou pela política administrativa. Por outro, explicita que não teremos saída senão deixarmos de lado uma postura de lamentação e/ou denúncias das injustiças e adotarmos uma postura ativa que, partindo de nossas contradições, (re)construa propostas concretas e efetivas frente à racionalidade neoliberal.

Nessa direção, Campos ${ }^{51(25)}$ defende um compromisso intransigente com o "agir paidéia", que desenvolve integralmente as pessoas ao "assegurar capacidade de compreensão e de decisão aos vários setores envolvidos em um projeto"51(25), estabelecendo outros padrões relacionais entre elas e as envolvendo na defesa da própria saúde. A intenção de operar o projeto ético-político do SUS e do País num "agir paidéia"51(25) faz mais sentido do que nunca frente ao aumento e à circulação de discursos de ódio, que tentam classificar determinadas vidas como passíveis de serem ceifadas. 
Em que pese o nosso compromisso com a diversidade, a busca constante de diálogo na ESF com os territórios e uma série de políticas arrojadas de saúde - nacional e localmente - para garantia de direitos a segmentos populacionais específicos - como pessoas LGBT, povos indígenas, pessoas com deficiência, pessoas em situação de rua ou em privação de liberdade - sabemos que há muito por se fazer na direção de um "agir paideia"51(25). Precisamos operar os princípios ético-políticos do SUS num movimento de defesa crescente e radical das singularidades expressas nos corpos, afetos e modos de estar no mundo em todos os espaços da vida e podemos fazê-lo por nossa capilaridade, abertura ao diálogo com as necessidades de saúde e quantidade de trabalhadores espalhados no País.

Quando aborda o enfrentamento da lógica necropolítica neoliberal, Valverde ${ }^{23}$ propõe como antídoto estratégias que mobilizem o desejo de compartilhar e construir iniciativas comuns, que agreguem grupos e ideias plurais, investindo em reunir o que o poder do capital quer dividir. A autora salienta que para tanto é preciso vincular discursos e práticas de forma crítica e criativa a uma empatia radical, a qual tende a emergir mais potente quanto mais articulada aos espaços onde a exclusão/opressão vive.

Sinergicamente, Butler ${ }^{17(164)}$ afirma que a vulnerabilidade é uma característica de nossa experiência. Somos seres que dependemos dos outros e "de um mundo sustentado e sustentável”. Tal marca da nossa experiência, que se dá, objetiva e subjetivamente, de forma diferenciada a depender do lugar que ocupamos no eixo espaço-temporal, é o que podemos mobilizar coletivamente para reexistir e resistir à necropolítica.

No diálogo com Campos ${ }^{51,52}$, Valverde ${ }^{23} \mathrm{e}$ Butler ${ }^{17}$, mirando o acúmulo de experiências potentes de melhoria da qualidade de vida desenvolvidas na e a partir da saúde pública brasileira e buscando estratégias solidárias e não violentas para consolidar as palavras do poeta “apesar de você, amanhã há de ser outro dia"53, afirmamos que o SUS pode muito.

Frente ao avanço da necropolítica neoliberal, que agora, mais do que nunca, parece contagiar as máquinas do Estado, entendemos que há que se radicalizar o projeto ético-político que possibilitou existir um SUS e (re)construí-lo como um projeto civilizatório.

Defendemos que é partindo da realidade concreta, plural e contraditória de nossos saberes, práticas, trabalhadores e usuários que podemos disputar corações e mentes para resgatar um projeto nacional de desenvolvimento fundado na equidade. Olhando para trás, para essa história de pouco mais de trinta anos, e tudo que fizemos acontecer no Brasil - país marcado por opressões, desigualdades e autoritarismos -, ousamos afirmar que é possível reaquecer nossos espaços de participação social, de articulação intersetorial, de mobilização popular a fim de reagir às investidas necropolíticas neoliberais.

\section{Considerações finais}

A defesa de narrativas machistas, racistas, LGBTfóbicas e xenófobas vêm sendo (re) reproduzida, em maior ou menor escala, há muitos anos. Contudo, a partir do início da campanha eleitoral de 2018 relatos desse tipo de intolerância nas redes sociais se espalharam com especial vigor. Os discursos de ódio e sua produção de relações de inimizade ${ }^{\mathbf{1 2}}$ buscam constranger a política como meio de resolução de conflitos. A 'novidade' no contemporâneo parece ser a magnitude que alcançam com suporte das tecnologias digitais de comunicação. Bem como sua proliferação a partir de ocupantes de cargos no governo federal, que entoam seu saudosismo do passado mais sombrio da história nacional e naturalizam os índices vergonhosos de mortes anuais associadas à violência contra mulher, à LGBTfobia e ao genocídio da juventude negra, demarcando que nossas vidas - algumas delas! - são descartáveis. 
A tese que defendemos neste texto é de que o SUS é um dos mais efetivos contravenenos à necropolítica no Brasil. O SUS constitui-se elemento político e tático para enfrentar as pautas autoritárias e conservadoras nos costumes, irresponsáveis nas questões ambientais, anticientíficas na produção de conhecimento, anti-seculares na condução do Estado e genocidas na gestão da vida.

Sistema universal de saúde num país com mais de 200 milhões de habitantes, o SUS traz em sua biografia um sopro vanguardista e vem nos dando - a 'nós, o povo' - demonstrações teóricas e práticas de sua importância para pensar a política como espaço democrático de participação e concertação. Apesar da conjuntura, segue investindo na discordância como possibilidade de reflexão e no tensionamento como parte da articulação e pactuação de políticas públicas comprometidas com a defesa inegociável da vida e de todos os modos de viver. Por sua capacidade de se agigantar, expandir, acomodar e incluir, o SUS tem um papel estratégico para recuperar o presente, mas também para escrever um nosso futuro.

Apesar da escalada necropolítica que analisamos - e mesmo diante das justas críticas da sociedade às falhas do sistema -, os mais radicais detratores do papel social do Estado não são capazes de encontrar apoio na arena pública para propor abertamente o seu fim, sendo necessário que recorram a sucessivas cortinas de fumaça para atacar o SUS.

Como diz Gandhi, cada vez que se dá um passo adiante a ordem existente é perturbada,

quando uma sociedade inteira avança, esse atropelo se faz em uma escala muito maior; e cada coisa que transtornar os interesses criados que quiser suprimir - tudo! - se transforma em um obstáculo54.

Nosso sistema de saúde e seus princípios transtornaram e transtornam os interesses do neoliberalismo. Por isso mesmo, o SUS segue potente para superarmos os atuais obstáculos e disputarmos corações e mentes na defesa de um projeto nacional de desenvolvimento popular, soberano e solidário.

\section{Colaboradores}

Agostini R (0000-0001-8071-9362)* e Castro AM (0000-0003-1190-5828)* contribuíram igualmente para a concepção, planejamento, análise, elaboração e aprovação final do manuscrito. 


\section{Referências}

1. Melo EA. O que pode o Mais Médicos? Ciênc. Saúde Colet. 2016; 21(9):2672-2674.

2. Brasil. Constituição, 1988. Constituição da República Federativa do Brasil: promulgada em 5 de outubro de 1988. Brasília, DF: Senado Federal, 2016. [acesso em 2020 fev 21]. Disponível em: https://www2.senado. leg.br/bdsf/bitstream/handle/id/518231/CF88_Livro_EC91_2016.pdf.

3. Brasil. Ministério da Saúde, Secretaria de Atenção à Saúde, Departamento de Atenção Básica. Saúde da família no Brasil. Uma análise de indicadores selecionados: 1998-2005/2006 Brasília, DF: Ministério da Saúde; 2008.

4. Instituto de Pesquisa Econômica Aplicada. Objetivos de Desenvolvimento do Milênio: Relatório Nacional de Acompanhamento. Brasília, DF: Ipea; 2014.

5. Brasil. Ministério da Saúde, Secretaria de Vigilância em Saúde, Departamento de Vigilância de Doenças e Agravos Não Transmissíveis e Promoção da Saúde. Saúde Brasil 2014: uma análise da situação de saúde e das causas. Brasília, DF: Ministério da Saúde; 2015.

6. Sanches D, Contarato A, Oliveira W. Cobertura de vacina contra sarampo voltou ao patamar dos anos 2000; número de internações pela doença saltou de 33 casos para 135 em três anos [internet]. [acesso em 2019 ago 13]. Disponível em: http://dapp.fgv.br/doencas-imunopreviniveis-uma-analise-das-estatisticas-oficiais-de-saude-para-enfermidades-com-prevencao/.

.7. Brasil. Ministério da Saúde, Secretaria de Vigilância em Saúde, Departamento de Vigilância de Doenças e Agravos não Transmissíveis e Promoção da Saúde. Saúde Brasil 2017: uma análise da situação de saúde e os desafios para o alcance dos objetivos de desenvolvimento sustentável [internet]. Brasília, DF: Ministério da Saúde; 2018. [acesso em 2020 fev 7]. Disponível em: http://bvsms.saude.gov.br/bvs/publicacoes/ saude_brasil_2017_analise_situacao_saude_desafios_ objetivos_desenvolvimento_sustetantavel.pdf.
8. Silva SP. A trajetória histórica da segurança alimentar e nutricional na agenda política nacional: projetos, descontinuidades e consolidação. Texto para discussão. Instituto de Pesquisa Econômica Aplicada. Brasília, DF: Ipea; 2014.

9. Pinto HS. A Segurança Alimentar e Nutricional no Brasil (Parte 1): A Modernização do Estado e os Avanços na Superação da Fome [internet]. Brasília, DF: Núcleo de Estudos e Pesquisas. [acesso em 2019 set 19]. Disponível em: www.senado.leg.br/estudos.

10. Dardot P, Laval C. A nova razão do mundo. Ensaio sobre a sociedade neoliberal. São Paulo: Boitempo; 2016.

11. Marx K. O capital. Rio de Janeiro: LTC; 1982.

12. Mbembe A. Necropolítica, biopoder, soberania, estado de exceção, política da morte. São Paulo: n-1 edições; 2018.

13. Rodrigues C. Capitalismo informacional, redes sociais e dispositivos móveis: hipóteses de articulação. Galáxia. 2010; (20):70-83.

14. Araújo JD. Polarização epidemiológica no Brasil. Epidemiol. Serv. Saúde [internet]. 2012 [acesso em 2019 set 9]; 21(4):533-538. Disponível em: http://scielo. iec.gov.br/scielo.php?script=sci_arttext\&pid=S1679$-49742012000400002 \& \operatorname{lng}=$ pt.

15. Duarte EC, Barreto SM. Transição demográfica e epidemiológica: a Epidemiologia e Serviços de Saúde revisita e atualiza o tema. Epidemiol. Serv. Saúde [internet]. 2012 [acesso em 2019 set 9]; 21(4):529-532. Disponível em: http://scielo.iec. gov.br/scielo.php?script=sci_arttext\&pid=S1679$-49742012000400001 \& \operatorname{lng}=$ pt.

16. Ocké-Reis CO. SUS: o desafio de ser único. In: Santos NR, Amarante PDC, organizadores. Gestão Pública e Relação Público Privado na Saúde. Rio de Janeiro: Cebes; 2011, p. 101-114. 
17. Butler J. Corpos em aliança e a política das ruas: notas para uma teoria performativa de assembleia. Rio de Janeiro: Civilização Brasileira; 2018.

18. Escorel S. Reviravolta na Saúde, origem e articulação do movimento sanitário. Rio de Janeiro: Fiocruz; 1999.

19. Escorel S. Equidade em Saúde. Dicionário da Educação Profissional em Saúde [internet]. [acesso em 2019 set 17]. Disponível em: http://www.sites.epsjv. fiocruz.br/dicionario/verbetes/equsau.html.

20. Campos GWS. Reforma da reforma: repensando a saúde. São Paulo: Hucitec; 2006.

21. Fleury S, Ouverney AM. Política de Saúde: uma política social. In: Giovanella, L, Escorel S, Lobato LVC, et al. Políticas e Sistema de Saúde no Brasil. Rio de Janeiro: Fiocruz; 2008, p. 23-64.

22. Reigada CLL, Romano VF. O uso do SUS como estigma: a visão de uma classe média. Physis. 2018 [acesso em 2019 set 17]; 28(3):e280316. Disponível em: https:// scielosp.org/article/physis/2018.v28n3/e280316/.

23. Valverde C. De la necropolítica neoliberal, a la empatía radical. Violencia discreta, cuerpos excluidos y repolitización. Madrid: Icaria; 2015.

24. Souza J. A Elite do atraso: da Escravidão à lava jato. São Paulo: Leya; 2017.

25. Ribeiro D. O povo brasileiro: a formação e o sentido do Brasil. São Paulo: Global; 2015.

26. Dias AFL. A democracia como vítima do golpe tragicômico de 2016 no Brasil. Argumentos. 2018 [acesso em 2019 set 17]; 10(19):62-72. Disponível em: http://periodicos.ufc.br/argumentos/article/view/32018/72329.

27. Hoefel MGL, Severo DO, Pordeus AR. Reforma Trabalhista no Brasil e a Saúde do Trabalhador: uma ponte para o século XIX. Tempus. 2018; 12(1):59-71.

28. Costa BS, Costa SS, Cintra CLD. Os possíveis impactos da reforma da legislação trabalhista na saúde do trabalhador. Rev Bras Med Trab. 2018; 16(1):109-17.

29. Brasil. Proposta de Emenda à Constituição 06 de 2019 [internet]. 2019. [acesso em 2019 maio 5]. Disponível em: https://www.camara.leg.br/proposicoesWeb/prop_mostrarintegra?codteor $=1712459 \&$ file name $=\mathrm{PEC}+6 / 2019$.

30. Instituto Brasileiro de Geografia e Estatística. Tábuas Completas de Mortalidade, 2018. [acesso em 2019 maio 5]. Disponível em: https://biblioteca.ibge.gov. br/visualizacao/periodicos/3097/tcmb_2018.pdf.

31. Instituto Brasileiro de Geografia e Estatística. Pesquisa Nacional por Amostra de Domicílios - Contínua (PNAD-C), 2019. [acesso em 2019 maio 5]. Disponível em: https://www.ibge.gov.br/estatisticas/sociais/ trabalho/9173-pesquisa-nacional-por-amostra-de-domicilios-continua-trimestral.html? $=\& \mathrm{t}=$ downloads .

32. UOL. Bolsonaro diz que governo vai "desburocratizar" normas de saúde e segurança no trabalho [internet]. [acesso em 2019 maio 14]. Disponível em: https:// economia.uol.com.br/noticias/reuters/2019/05/13/ bolsonaro-diz-que-governo-vai-desburocratizar-normas-de-saude-e-seguranca-do-trabalho.htm.

33. Organização Internacional do Trabalho. Uma década de promoção do trabalho decente no Brasil: uma estratégia de ação baseada no diálogo social. Genebra: OIT; 2015.

34. Cerqueira D, Lima RS, Bueno S, et al. Atlas da violência 2018. Rio de Janeiro: IPEA; 2018.

35. Waiselfisz JJ. Mapa da Violência 2016. Brasília, DF: Flacso; 2016.

36. Brasil. Decreto ${ }^{\circ} 9.685$, de 15 de janeiro de 2019 [internet]. Diário Oficial da União. 2019 Jan 15. [acesso em 2019 maio 5]. Disponível em: http://www.planalto.gov.br/ccivil_03/_Ato2019-2022/2019/Decreto/ D9685.htm.

37. Brasil. Decreto $\mathrm{n}^{\circ}$ 9.785, de 7 de maio de 2019 [internet]. Diário Oficial da União. 2019 Maio 7. [acesso em 2019 maio 15]. Disponível em: http://www.pla- 
nalto.gov.br/ccivil_03/_ato2019-2022/2019/decreto/D9785.htm.

38. Fundação Oswaldo Cruz. Nota técnica. Análise do Projeto de Lei no 6299/2012 [internet]. [acesso em 2019 ago 15]. Disponível em: https://portal.fiocruz. br/sites/portal.fiocruz.br/files/documentos/nota tecnica_pl_agratoxicos.pdf.

39. Pinto LF, Giovanella L. Do Programa à Estratégia Saúde da Família: expansão do acesso e redução das internações por condições sensíveis à atenção básica. Ciênc. Saúde Colet. 2018; 23(6):1903-1913.

40. Rassela D, Hone T, Souza LE, et al. Mortality associated with alternative primary healthcare policies: a nationwide microsimulation modelling study in Brazil. BMC Med. 2019 [acesso em 2020 fev 8]; 17:82. Disponível em: https://bmcmedicine.biomedcentral. com/articles/10.1186/s12916-019-1316-7.

41. Rassela D, Basu S, Hone T, et al. Child morbidity and mortality associated with alternative policy responses to the economic crisis in Brazil: A nationwide microsimulation study. PLoS Med. 2018 [acesso em 2020 fev 8]; 15(5):e1002570. Disponível em: https:// journals.plos.org/plosmedicine/article?id=10.1371/ journal.pmed.1002570.

42. Brasil. Ministério da Saúde, Secretaria de Atenção à Saúde. Nota técnica ${ }^{\circ}$ 11/2019. [acesso em 2019 maio 7]. Disponível em: http://pbpd.org.br/wp-content/ uploads/2019/02/0656ad6e.pdf.

43. Organização das Nações Unidas. A ONU e a resposta à Aids no Brasil. Brasília, DF: ONU; 2008.

44. Conselho Federal de Medicina. Opinião dos brasileiros sobre o atendimento na área de saúde [internet]. 2014. [acesso em 2019 maio 5]. Disponível em: https://portal.cfm.org.br/images/PDF/apresentao-integra-datafolha203.pdf.

45. Conselho Federal de Medicina. Opinião dos brasileiros sobre o atendimento público na área de saúde. 2018. [acesso em 2019 maio 5]. Disponível em: https://portal. cfm.org.br/images/PDF/datafolha_sus_cfm2018.pdf.
46. Conselho Nacional de Secretários de Saúde. $77 \%$ dos brasileiros aprovam o atendimento do SUS. 2018. [acesso em 2019 set 9]. Disponível em: https://www. conass.org.br/77-dos-brasileiros-aprovam-o-atendimento-do-sus/.

47. Villela W, Monteiro S. Atenção à saúde das mulheres: historicizando conceitos e práticas. In: Villela W, Monteiro S, organizadores. Gênero e Saúde: Programa Saúde da Família em questão. Rio de Janeiro: Abrasco; Brasília, DF: UNFPA; 2005.

48. Kalckmann S, Santos CG, Batista LE, et al. Racismo Institucional: um desafio para a equidade no SUS? Saúde Soc. 2007; 16(2):146-155.

49. Santos ALM. O estado da arte sobre as barreiras no acesso à saúde para travestis e transexuais. [trabalho de conclusão de curso em medicina]. Salvador: Universidade Federal da Bahia; 2016. 51 p.

50. Guimarães RCP. Estigma e Diversidade Sexual nos Discursos dos (as) profissionais do SUS: Desafios para a saúde da população LGBT [tese]. Salvador: Universidade Federal da Bahia; 2018. 176 p.

51. Campos GWS. Saúde Paideia. São Paulo: Hucitec; 2003.

52. Campos GWS. A saúde pública e a defesa da vida. São Paulo: Hucitec; 2006.

53. Hollanda CB. Apesar de você. 1978. [acesso em 2019 maio 20]. Disponível em: https://analisedeletras.com. br/chico-buarque/apesar-de-voce/.

54. Quaresma I. Sustentação Oral no plenário do STF. [acesso em 2019 maio 20]. Disponível em: https:// www.youtube.com/watch?v=HR3PPnKhS8k.

Recebido em 02/06/2019

Aprovado em 11/08/2019

Conflito de interesses: inexistente

Suporte financeiro: não houve 